\title{
Fish Bone Migrating into the Thyroid Gland
}

\author{
J ay Kantilal Kotecha
}

\begin{abstract}
Many cases have been reported in the literature about foreign bodies lodged in the hypopharynx. A foreign body penetrating the esophagus and migrating into the soft tissue of neck is a rare phenomenon. We report a case of 35 years male who ingested a fish bone which then migrated into left lobe of thyroid and the role of imaging in its detection and management.
\end{abstract}

Keywords: Foreign body, Thyroid gland, Migration.

How to cite this article: Kotecha J K. Fish Bone migrating into the Thyroid Gland. Int J Head Neck Surg 2014;5(1):42-44.

\section{Source of support $\mathrm{Nil}$}

\section{Conflict of interest None}

\section{INTRODUCTION}

One of the most common foreign bodies to be lodged in the upper gastrointestinal ( $\mathrm{Gl}$ ) tract is a fish bone. But a fish bone perforating the esophagus and then subsequently migrating into the soft tissue of neck is rare, and even rarer is its migration into the thyroid gland. When a foreign body has migrated into the soft tissues of the neck, it is very likely that it causes secondary infections and needs surgical intervention. The role of imaging in such cases is diagnosing and determining the precise location of the foreign body and its retrieval. Plain $X$-ray is generally the first imaging modality used and is able to detect radi opaque foreign bodies like fish bones. Plain $\mathrm{X}$-rays provide limited information and do not provide the exact relationship of the foreign body with other structures of the neck. Computed tomography (CT) scans are used to determine the exact location of the foreign body and its relationship with the surrounding structures and is thus useful in hel ping plan surgical extraction. Ultrasonography (USG) is also very sensitive in diagnosing and determining the location of the foreign body.

\section{CASE REPORT}

A 35-year-old male presented to the ENT clinic at our hospital with history of dysphagia since 15 days. The patient gave history of ingesting a fish bone 15 days prior

Clinical Associate

Department of Radiology, Lilavati Hospital, Mumbai Maharashtra, India

Corresponding Author: J ay Kantilal Kotecha, Department of Radiology, Lilavati Hospital, Mumbai, Maharashtra, India Phone: 9619452654, e-mail: kotechajay07@ gmail.com to presentation following which the complaints started. A fiberoptic laryngoscopy did not reveal any evidence of foreign body and was normal. A lateral radiograph showed a linear radiopacity in the region of cricopharynx suggestive of a foreign body (Fig. 1).

The findings of the radiograph and fiberoptic laryngoscopy did not match, the patient was sent for CT scan of neck. Computed tomography scan revealed a radiodense foreign body lodged in the left lobe of thyroid gland, its upper end abutting the esophagus and lower end in the left lobe of thyroid (Figs 2 to 5 ).

A n ultrasound done later demonstrated a linear echogenic structure with posterior acoustic shadowing in the left lobe of thyroid gland, its upper end abutting the cricopharynx on left side and its lower end lying just below the capsule of left lobe of thyroid (Fig. 6).
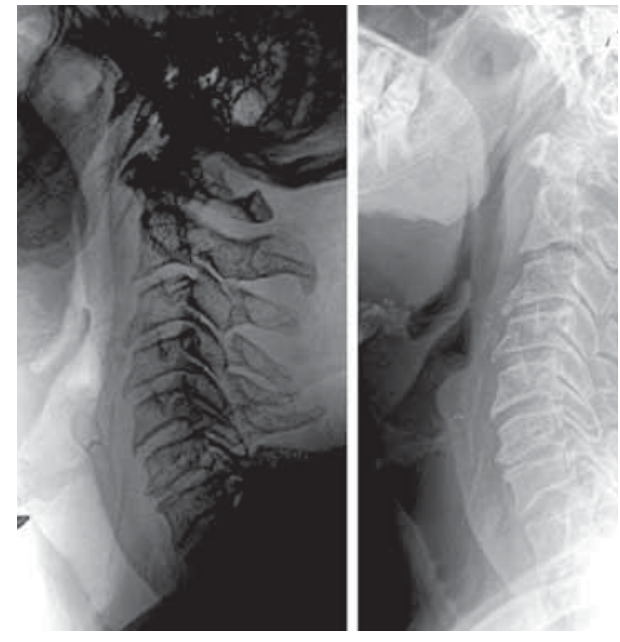

Fig. 1: Fish bone in thyroid gland as seen on lateral neck radiograph

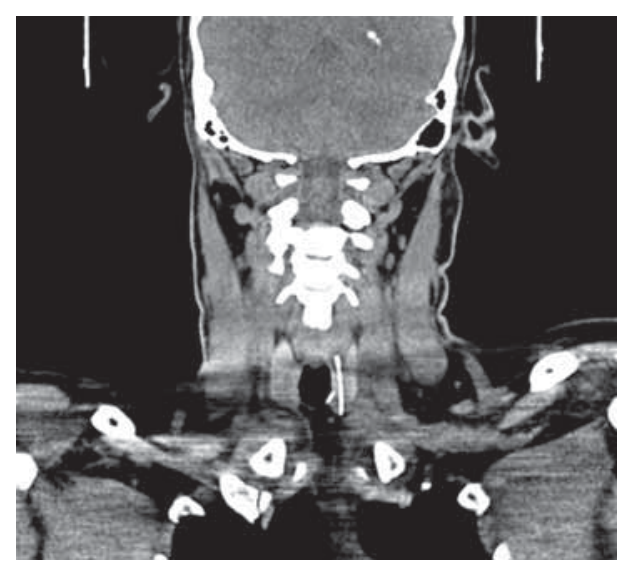

Fig. 2: Computed tomography coronal image 


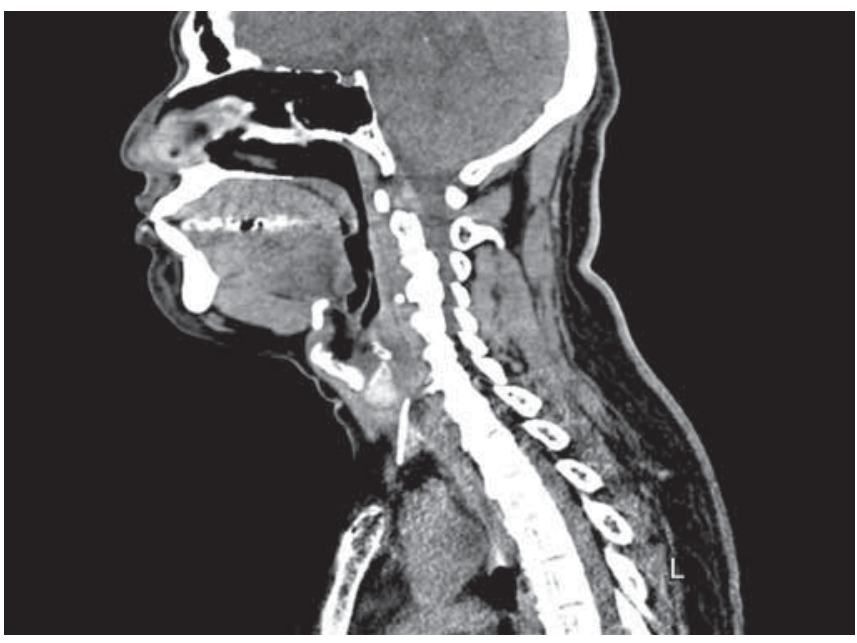

Fig. 3: Computed tomography sagittal image

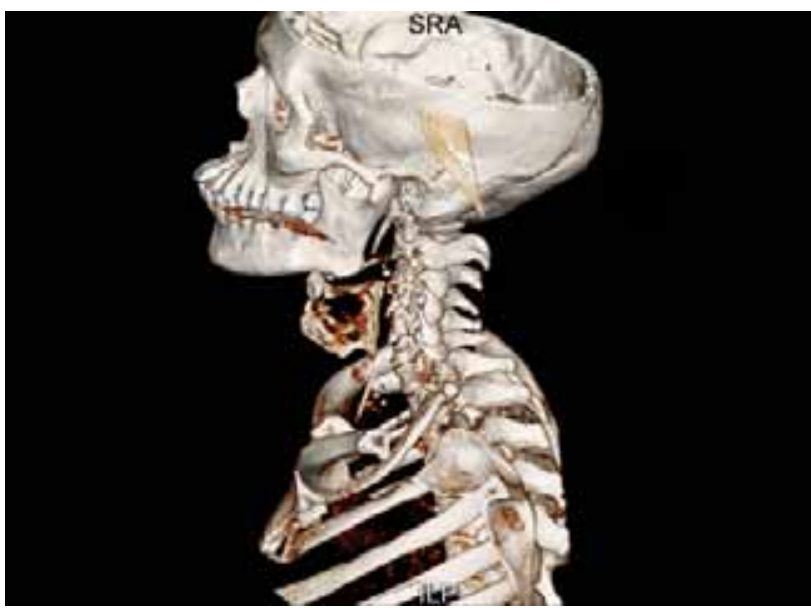

Fig. 5: Three-dimensional CT reconstruction

Neither CT nor ultrasound showed any evidence of infection or inflammation around the foreign body. The patient was posted for surgery for removal of the foreign body. Neck exploration was done and a $4 \mathrm{~cm}$ size linear fish bone was removed. No evidence of infection was found in or around the thyroid gland. The procedure was uneventful.

\section{DISCUSSION}

Ingestion of a fish bone is a common emergency in the ENT clinic. This occurs frequently in A sian population, where it is common to eat fish that has not been deboned. ${ }^{1}$ Fish bones can pass spontaneously through the digestive tract. On occasion, it can get impacted in the tonsils, base of tongue, pharynx or valleculae and can be removed with minimal morbidity. In a few cases, the foreign body gets lodged at one of the constrictions along the esophagus, requiring removal by rigid esophagoscopy under general anesthesia. In even fewer cases, the foreign body penetrates the esophageal mucosa and migrates through it. In some instances, the foreign body can migrate completely through the esophageal wall. 'M igrating foreign bodies' is the term used for such cases. ${ }^{2} \mathrm{~A}$ migrated foreign body can remain silent or become

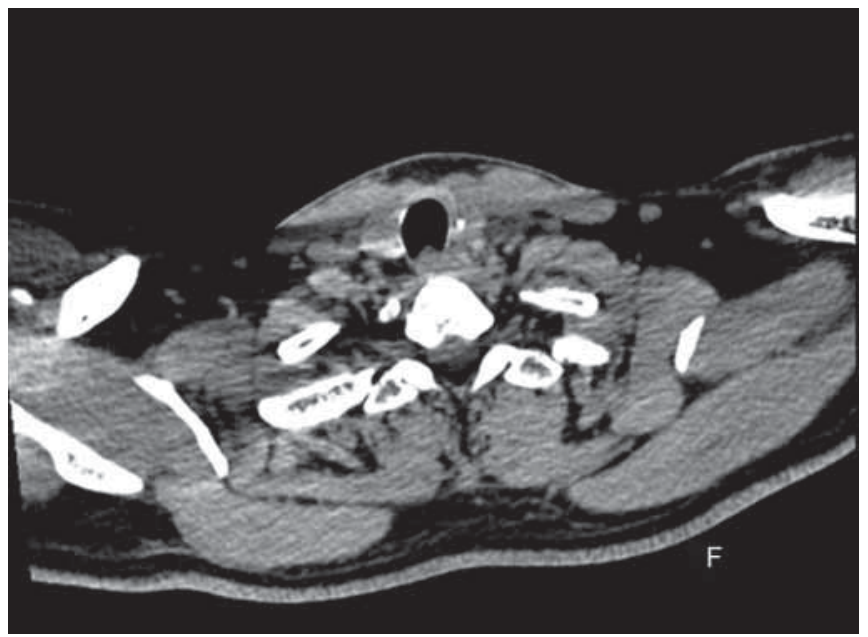

Fig. 4: Computed tomography axial image

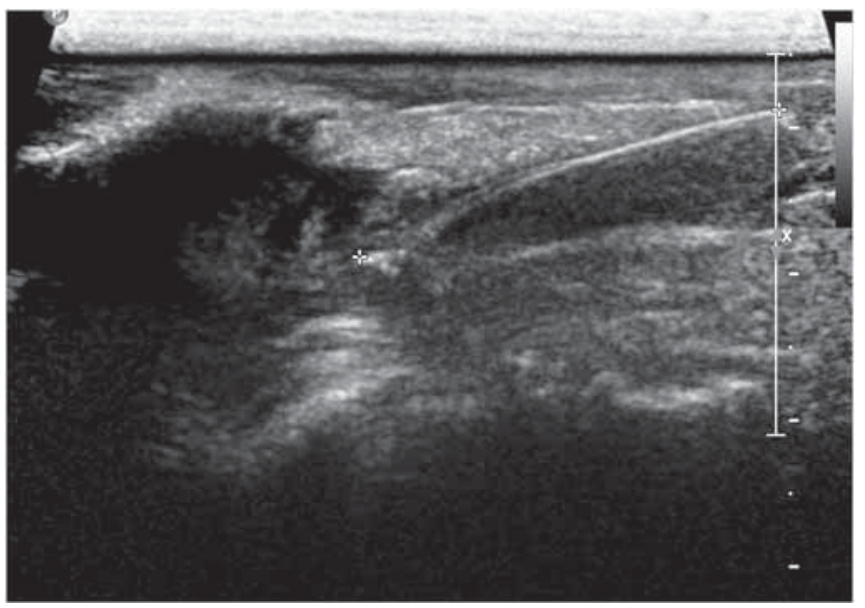

Fig. 6: Fish bone in thyroid gland as seen on USG

impacted in the soft tissues of the neck and cause serious suppurative or vascular complications.

In R emsen et al's series, ${ }^{3} 321$ cases of penetrating foreign bodies were reviewed from the literature and only 43 were found extraluminally.

Chee and Sethi ${ }^{4}$ reported a series of migrated foreign bodies in the neck. All of the foreign bodies in their series were sharp and linear.

Goh and $\operatorname{Tan}^{5}$ described a series of four cases where fish bones penetrated the esophagus and migrated into the thyroid gland, over a period of 11 years. A II of these bones were successfully removed by neck exploration with only one case requiring thyroid lobectomy.

AI M uhanna ${ }^{6}$ et al described a case in which repeated esophagoscopy failed to locate any foreign body in a patient with painful dysphagia, following which a CT scan was done that showed a fish bone embedded in the right thyroid lobe.

Sethi and Stanley ${ }^{7}$ described two cases of fish bones penetrating the esophagus and showed that $\mathrm{CT}$ was the investigation of choice for localizing the foreign body.

$X$-rays of the neck, though useful, do not help to determine, if migration has occurred. Foreign-body migration 
is suspected on the basis of suggestive history, a positive finding on lateral neck radiography, and a negative finding on rigid esophagoscopy. A CT scan or an USG can then be used to localize the foreign body and estimate the extent of damage done. When such a patient presents, management involves exploration of the neck by an external approach to identify the foreign body and remove it. In practice, this is often a difficult task. The main difficulty is the localization of the foreign body in the soft tissue, after which removal is usually simple. The position of the foreign body at surgery may be different from that when the CT scan was done as the soft tissues of the neck are mobile in relation to the bony and cartilaginous structures. Systemic exploration of the neck via an external approach using the CT scan as a guide will decrease the chances of an unsuccessful exploration. Removal of the foreign body will prevent the occurrence of life-threatening complications.

\section{CONCLUSION}

One must be aware of the changing nature of the patient's complaints. A case involving persistent pain in neck, history of ingestion of foreign body and negative endoscopy should al ert the physician to the possibility of a penetrating, migrating foreign body in the thyroid gland. Cervical USG and a CT scan of the neck should be performed to investigate whether there is migration to the thyroid gland. Cervical USG is as good as CT scan in detecting a foreign body in the thyroid gland.

\section{REFERENCES}

1. Lin $\mathrm{YH}, \mathrm{HOHC}, \mathrm{H}$ siao HS. An ingested fish bone migrating to the thyroid gland-a case report. Tzu Chi Med J 2006;18(6): 438-441.

2. Zohra T, Ikram M, Iqbal M, A khtar S, A bbas SA. M igrating foreign body in the thyroid gland - an unusual case. J Ayub M ed Coll A bbottabad 2006;18(3):65-66.

3. Remsen K, Lawson W, Biller HF, Som ML. Unusual presentations of penetrating foreign bodies of upper GIT. Ann Otol Rhinol Laryngol Supp 1983;105:32-44.

4. Chee LW, Sethi DS. Diagnostic and therapeutic approach to migrating foreign bodies. Ann Otol Rhinol Laryngol 1999;108:177-180.

5. Goh YH, Tan NG. Penetrating oesophageal foreign bodies in the thyroid gland. J Laryngol Otol 1999;113:769-771.

6. M uhanna AA, A bu Chra KA, Dasti H, Behbehani A, AI-N aqeeb $\mathrm{N}$. Thyroid lobectomy for removal of a fish bone. J Laryngol Otol 1990;104:511-512.

7. Sethi DS, Stanley RE. M igrating foreign bodies in the upper digestive tract. A nn A cad M ed Singapore 1992;21(3):390-393. 